\title{
THE EXUDATION OF ICE FROM STEMS OF PLANTS.*
}

\author{
BY \\ W. W. COBLENTZ, Ph.D., \\ Associate Physicist, Bureau of Standards.
}

\section{INTRODUCTION.}

NoctUR $A$ L radiation is generally a passing of radiant energy from terrestrial substances into space. On a clear night the rate at which radiation passes outward from the earth's surface is very great, amounting to almost one-tenth of the solar constant. Of course, not all substances lose heat at this rate. This loss of heat by radiation produces pectliar formations of ice, some of which will now be mentioned.

Ground Ice.-The most familiar freak of ice formation occurs on bare, clayey soils which contain a certain (minimum) amount of moisture. If the moisture content of the soil falls below this minimum valute (which no doubt varies for different soils), then evaporation occurs as rapidly as the moisture is brought to the surface (by capillary action) and no ice is formed. $\Lambda$ ccording to the writer's observations, the ice is formed in contact with a nucleus which may be a grain of sand, a small pebble, etc. The earthy material has a higher emissivity than the water, it cools the more rapidly and the water is frozen to the under side of the nuclets, $\Lambda$ s heat is lost, more ice is formed, and, as it accumulates, rises in columns, as is to be observed everywhere on cold mornings. The watcr is supplied by capillary movement in the soil, from the surface of which the ground ice may be readily lifted, since in ireezing weather the ice is not frozen into the soil. ${ }^{1}$ The gencral experience is to find the ground ice supporting a nucleus (say a grain of sand, or even large stones$3 \times 1 / 2 \times 1$ inches in size). The nuclei may be thinly distributed. The writer has observed several large areas, $3 \times 1 / 2$ feet, which did not contain nuclei, from which it appears that this type of ice formation can occur without having a nucleus (gravel, etc.) to start the refrigeration.

* Communicated by the Author.

${ }^{1}$ Abbe, Amer. Meteorological Jour, 9, p. 523, I893. 
Anchor Ice.-Barnes ${ }^{2}$ has made a prolonged study of the formation of anchor ice at the bottom of the St. Lawrence River. This kind of ice consists of fine spicules which adhere to the bottom of the river. It is a friable mass which may vary from six to eight feet in thickness. According to Barnes, this ice is formed as a result of the greater emissivity and hence the greater cooling of the material composing the river bottom.

Hoar-frost is another example of ice formation as the result of cooling by radiation. Here, however, the accepted explanation is that the ice spicules are formed by accretion, as the result of the deposition of moisture from the surrounding air.

The foregoing are familiar and interesting illustrations of ice formations on substances as the result primarily of the loss of heat by radiation. We have now to consider a rarer phenomenon, which is the subject of the present paper.

Ice Formations on Plants.-According to the writer's observations, the amount of ice formed upon a plant stem is a function of (I) the rate at which water can rise by capillary action in the sap tubes within the stem, (2) the ease with which the moisture can pass out to the surface, (3) the rate of evaporation from the surface (convection, wind-velocity), and (4) the emissivity of the surface of the stem. Instead of the title "Exudation of Ice," a more pretentious title would have been " The Capillary Movement of Water: An Experimental Demonstration by Means of the Formation of Ice Fringes on Plants." This might appear more scientific and one could discuss the capillary movement of water as a function of the temperature of the stem; the size of bore and number of (sap) tubes; the thickness and permeability of the walls of these tubes, etc. However, the present communication makes no pretence at such completeness of the investigation. In fact, the subject of ice formation forced itself upon the writer at a time when other duties were pressing, and hence it could not be given the attention it deserved. As a result, the experimental tests, to be described presently, were usually carried out only to the extent of refuting the various notions held by various persons as to the cause of this ice formation. All sorts of explanations were presented. This is the main reason for

" Ice Formation with Special Reference to Anchor Ice and Frazil," H. T. Barnes, Monthly Weather Review, May, I907, p. 225. 
giving in extenso these simple tests, which show that the formation of fringes of ice on plant stems is not the result of accretion, hydrostatic pressure, rifts in the stem, moisture in the bark, the presence of sap, etc., but that it is the result primarily of the capillary movement of water in the numerous sap tubes which are to be found in those plant stems upon which the ice formations are the most conspicuous.

\section{IT. HISTORICAL DATA.}

One of the earliest descriptions of the exudation of ice fringes from plants was published by $\mathrm{Herschel}^{3}$ about eighty years ago. His observations relate to the icy fringes which were formed around thistle stalks and stumps of heliotropes, many specimens of which were still green. Stephen Elliott ${ }^{4}$ had previously described a remarkable protrusion of fringes of ice from the stems of fleabane (Conyza bifrons).

The fullest account, with an attempted explanation of this phenomenon, was given by John Le Conte ${ }^{5}$ about 63 years ago. His observations are on two species of fleabane, Pluchea bifrons and Pluchea camphorata, which he found growing in wet soils, around ponds and along roadside ditches in the lowlands of South Carolina and Georgia. In these plants the root is perennial, but the stem is annual and herbaceous.

Le Conte's descriptions differ materially from my own. His observations appeared to establish the following facts in relation to the phenomenon:

I. "The depositions of ice are entirely confined to the immediate neighborhood of the roots of the plants, the upper parts of the tall, unbroken stalks being quite free from them. They frequently commence two or three inches from the ground, and extend from three to four inches along the axis of the stem. The stalks are dead, and quite dry to within about six inches of the earth, below which they are generally green and succulent. The plant has a large and porous pith, which is always saturated with moisture as high as six or seven inches from the base of the

* Sir John Herschel, Phil. Mag. (3), 2, p. I10, 1833.

"Stephen Elliott, "Sketch of the Botany of South Carolina and Georgia," published in I824, vol. 2, p. 322. Quoted by Le Conte.

- John Le Conte, Proc. Amer. Assoc. Adv. Sci., vol. 3, p. 20, 1850. 
stem." From this it would appear that the ice was formed on the green stems, as was true of many of the specimens of heliotrope described by Herschel.

2. "The ice emanates in a kind of riband, or frill-shaped, wavy, friable, semipellucid excrescence, the structure of which (quoting Herschel) is 'fibrous like that of the fibrous variety of gypsum, presenting a glassy, silky, wavy surface; the direction of the fibres being at right angles to the stem or horizontal." " Le Conte found that the number of ribands varied from one to five, which issued from the stems in vertical or longitudinal lines, often unsymmetrically displaced around the axis. He frequently observed the icy excrescences to exceed five inches in length; often curled back so that the remote extremity of the frill came close to the line of attachment to the stalk.

From this it may be noticed that the amount of ice formed is very considerable. Fvidently the moisture must come from within the plant. The amount of water congealed during a single night is vastly too great to come from the aqueous vapor in the atmosphere, hence the phenomenon cannot be a modification of hoar-frost. In fact, in the illustrations to be cited presently, which were observed by the writer, the excrescences of ice on one particular species of plant were formed every night which was sufficiently cool for ice formation, although there was little or no formation of hoar-frost anywhere in the vicinity.

3. Although the ice sheets appeared to protrude from the interior of the stem, both Herschel and I.e Conte found that usually the stems were solid and that the ice terminated at the surface. "The point of attachment of the ice was always the wood, beneath the outer bark or epidermis, which the frozen sheets had in every instance stripped off and forced out to a distance." When the frost was severe, Le Conte found that the ice riband was continutous with the frozen pith, through a longitudinal rift in the woody stem.

4. I.e Conte found that "the phenomenon took place in the same plant during several consecutive nights; and, when the wood was not rifted, frequently from the same portion of the stalk. When the wood was split, however, the deposition of ice occurred lower down the stem, at a part which was unaffected by the frost of the previous night. The stalks thus become completely rifted by a succession of severe nights, from the height. 
of six or seven inches down to the ground. This is unquestionably one of the reasons why these exudations of ice are seldom observed after the middle of the winter, for the stalks are usually destroyed before this period."

Le Conte considered the ice formation on plants to be a physical phenomenon, having no connection with the vitality of the stem. His explanation of the ice formation was that the moisture from the pith passes out along the wedge-shaped medullary rays which are to be found in abundance in this plant, and is frozen on the outside of the stem. II considered that the wedgeshaped medullary rays exerted a "projectile force" which brings the moisture to the surface. The extrdation of ice columns from the earth he referred to the same cause, viz., a rapid and forcible expansion along capillary tubes.

To the writer it does not appear necessary to postulate a complex "projectile force" to explain the ice fringes on plants. In fact, the plants upon which ice is formed in the greatest abundance have a preponderance of sap tubes, only an insignificant part of the stem being occupied by medullary rays.

Ward ${ }^{6}$ has given a rather popular description of the occurrence of ice fringes. He describes the fringes as projecting out horizontally, " not straight and stiff, but gently and gracefully curving or coiling into a beautiful, conch-Jike roll at the distal end." His observations were probalbly of short duration, otherwise he would have found but few instances in which the "fringes are attached at regular intervals around the stem, like paddles of a turbine wheel." He found that the bark was split into strips at the zone occupied by the ice sheets. He concluded that the ice had passed through these rifts in the bark. Jie thought that the water might have been pressed or drawn up through the cambium layer. He wisely dismisses the explanation because it "explained too much, since no reason can be assigned why the phenomenon should not be universal and not confined to one species." ' In the present paper microphotographs of the crosssections of various plants will assign this reason, viz., the difference in the porosity of the stems. I893.

"Ward, "Frost Freaks of the Dittany," Botanical Gazette, I8, p. I8 $8_{3}$

'Ward quotes Gray's Manual, I848, in which Helianthemum Canadense is described as behaving in a similar way. 
III. RECENT DATA.

During the past fall and winter (which may be called an "open" one, in that there was no snow until after December I, I913) the writer has been walking daily through Rock Creek Park, on his way to and from the Bureau of Standards. The route is along the "Beach Driveway," which winds along the east bank of the creek. This driveway is bordered by a steep hillside, from ten to fifty feet in height, which is thinly covered with second-growth trees, the majority of which are oaks and beeches. There is a thin undergrowth of grasses and of various herbaceous plants with annual stems and perennial roots.

From this it may be seen that the habitat of the plant about to be described is different from the one mentioned by Le Conte, which thrives on wet soils. The present observations are on Cunila mariana or Dittany, the stem of which is an herbaceous annual with perennial roots. This plant seems to thrive on dry ground even on bare hillsides, exposed to the blazing sun, where there is nothing but gravel and a few "asters." Other samples were found under trees where either the shade or the gravelly character of the soil prevented a luxuriant growth of other plants. The finest samples were found on a hillside which contained plenty of moisture, which was free from trees, but contained shrubbery.

The first observations were made on a frosty morning in November, I9I3. The first example, because of its white, ribbony character, was passed by, thinking it was something thrown from a passing carriage. The conspicuous white fibrous loops and ribbons drew my attention, and it was at once observed that they occurred upon only one species of herbaceous plant. A sample of the plant was sent to Prof. Cleveland Abbe, of the United States Weather Bureau, who pronounced this a rare and an interesting observation, which should be followed up by a more thorough study of the ice formations. While the problem itself seemed a very interesting one in radiation and in the capillary movement of water, it nevertheless seemed an intrusion upon a very busy program of radiation work, so that at first but little attention was given to it, other than scattered observations in passing to and from the Bureat. As time passed, many diverse opinions were received as to the cause of the ice formation. This 
called forth additional tests, so that the experimental data now at hand are rather voluminous. In view of the fact that memory is treacherous, notes were taken in the field at the time of observation.

Owing to the pressure of other problems requiring close attention, the tendency at the very first was to dismiss the subject by accepting I.c Conte's explanation that the moisture comes from the pith. This explanation was at once disproved, however, by the observations on the splinters of the Cunila stem, which formed ice always on the outside of the stem, but never on the pith. This, of course, should be expected, for pith is composed

Fig. I.

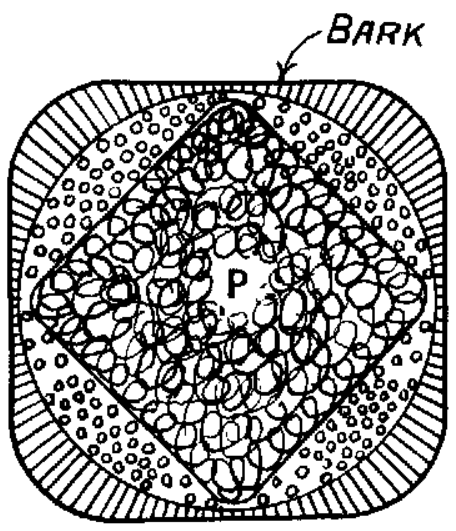

of small hexahedral cells along which water cannot pass by capillary attraction, and it would be very unlikely that it would be transferred by soaking through the cell walls.

Description of the Plant.-The stem of Cunila mariana is somewhat angular (especially as viewed with the bark on), having a cross-section of 1.5 to $2.5 \mathrm{~mm}$. The height of the stalk is from 25 to $30 \mathrm{~cm}$. (about I foot). The plant stems are very fragile, owing to the structure of the stems, which contain but little wood fibre. The plant is also weak in structure, owing to the great amount of pith and the manner in which the pith is arranged in the stem. As shown in Fig. I and Plate 5, the stem is somewhat rectangular in outline, the pith having a similar shape, but the "corners" are rotated 45 degrees. At these "corners" of the pith there is but little wood between the pith and the bark, 
and it is along this line that the stem often cracks. Perhaps this is the reason for the persistent belief among the few who are acquainted with the phenomenon that the ice ribbons come from these rifts in the stem. The small stem, weakened by splitting, is an easy prey to the wind.

Photographs were taken of thin sections across the stems of heliotrope, thistle, and also of an aster which was found near a Cunila stalk. The object in giving these microphotographs (which were very kindly prepared by Mr. E. D. Tillyer) is

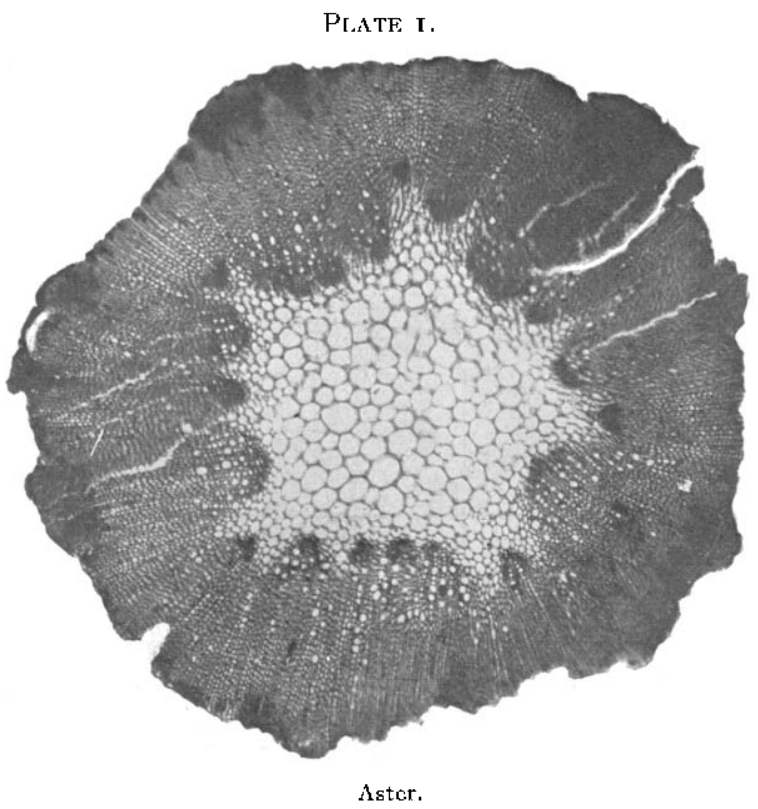

to show a typical example of plants which have but few sap tubes and which form little or no ice fringes; also typical examples of plants which have numerous sap tubes and which form an abundance of ice fringes.

The aster is typical of plants having but few sap tubes. As shown in Plate I, the woody structure is very compact, with but few sap tubes. All these microsections are magnified fifty times, from which one can obtain some idea of the great difference in porosity of the different plants.

On only one occasion was ice observed upon the stem of 
the aster. The ice was a small "tooth" formed close to the ground. From the section shown in Plate I it is evident that the structure of the wood fibre is so close that the moisture, which is drawn up within the stem by capillary attraction, can reach the surface of the stem at only a very slow rate. Hence the moisture disappears by evaporation as rapidly as it comes to the surface.

The thistle (Plate 2) and the heliotrope (I'late 3) stems have numerous large sap tubes. In the thistle stem there is a row

Plate 2.

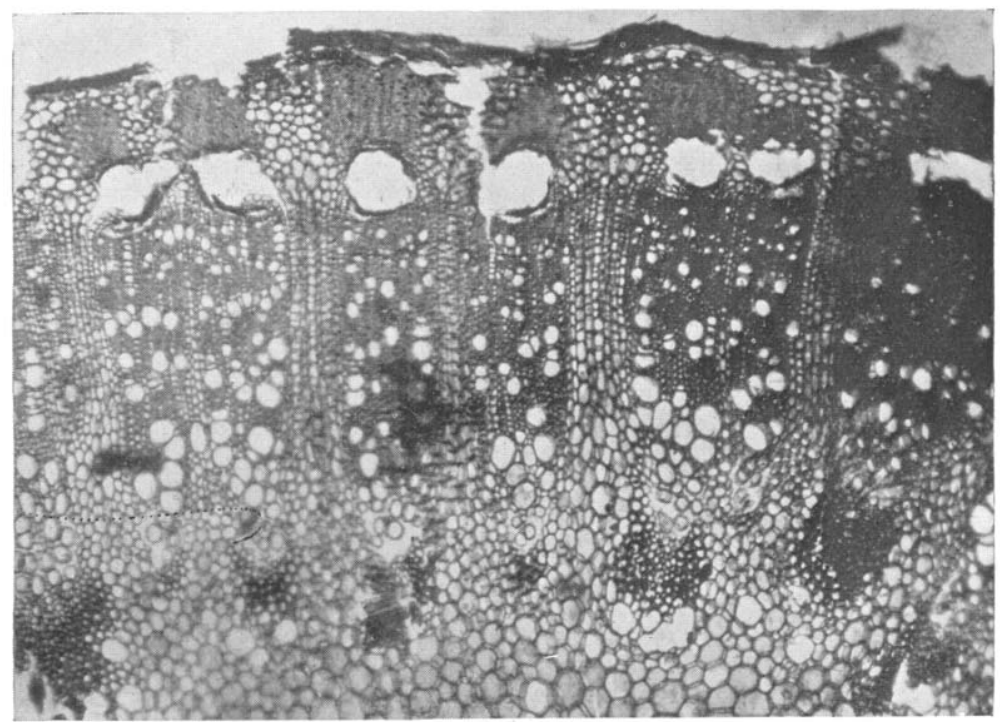

Thistle.

of large tubes situated near the bark. The presence of these large tubes filled with sap may explain the formation of ice fringes, as observed by Herschel.

Microphotographs of thin sections of Cunila are shown in Plates 4 and 5. The numerous holes in the wood are the "sap tubes," which form an easy path for the moisture to rise within the stem by capillary attraction. It would be interesting to determine to what extent this capillary movement of water is affected by the temperature of the surroundings.

The explanation of the formation of ice fringes, which are 
found to occur so abundantly upon the stems of the Cunila and which are not found upon other plants, is based upon the presence of a great number of closely adjoining sap tubes within the stem of the Cunila. But even the very woody portion of the base of the Cunila stem was found to be inactive in the formation of ice fringes.

It was found that the ice fringes rarely start from the side of the stem where the pith is closest to the bark. This eliminates, to some extent, the question whether the pith is instrumental in forming the ice fringes. In the splinters (and in the rifted stems of Cunila) at no time was ice found to have formed along the

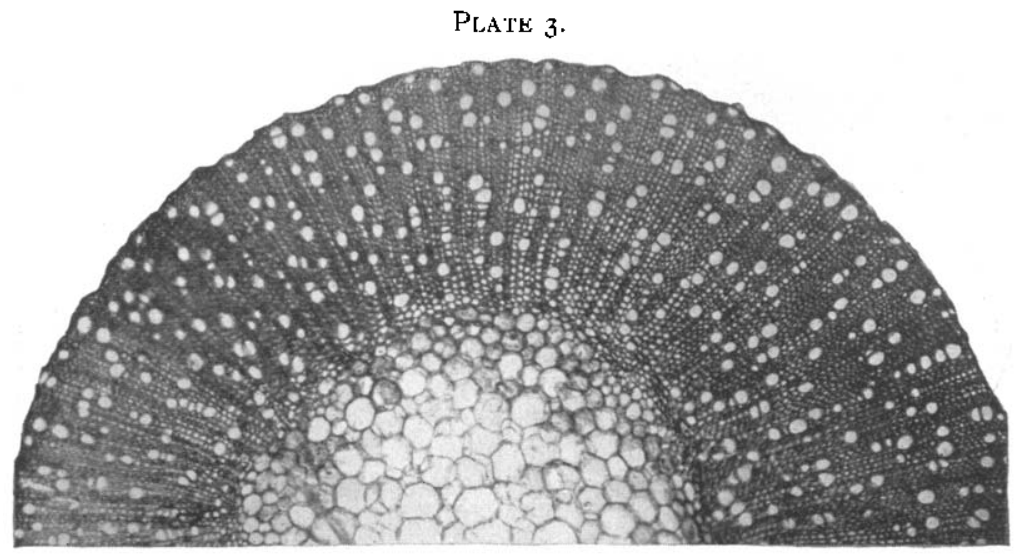

Heliotrope.

line of separation of the stem. This seemed puzzling at first, for it appeared to contradict the idea that the moisture comes from the sap tubes within the stem; in which case one would expect to find the formation of ice fringes facilitated upon the surface laid bare by splitting.

The microsections of the Cunila stems show in a very unexpected manner why no ice fringes are formed upon the rifted surface of the stem. $\Lambda$ s already stated, the rift always occurs at the "corners" of the pith where the woody part of the stem is the thinnest. In Plates 4 and 5 it may be noticed that at these four points, where the wood is the thinnest, usually there are but few if any sap tubes. Hence one need not expect to find ice formations upon the surfaces formed by splitting. 
Field and Laboratory Observations.-The field observations were made on isolated plants found scattered throughout the woods; also on three test-beds of plant-stems, without their roots, which were conveniently located along the roadway.

The first test-bed, Test No. r, was "planted" January 7 , I9I4, with plant stems ( 10 to $15 \mathrm{~cm}$. long) which had been in the laboratory since November, I9I3. This test contained (I) a stem and branches with bark intact; (2) a similar stem with two coats of shellac varnish; (3) a stem having the bark thoroughly

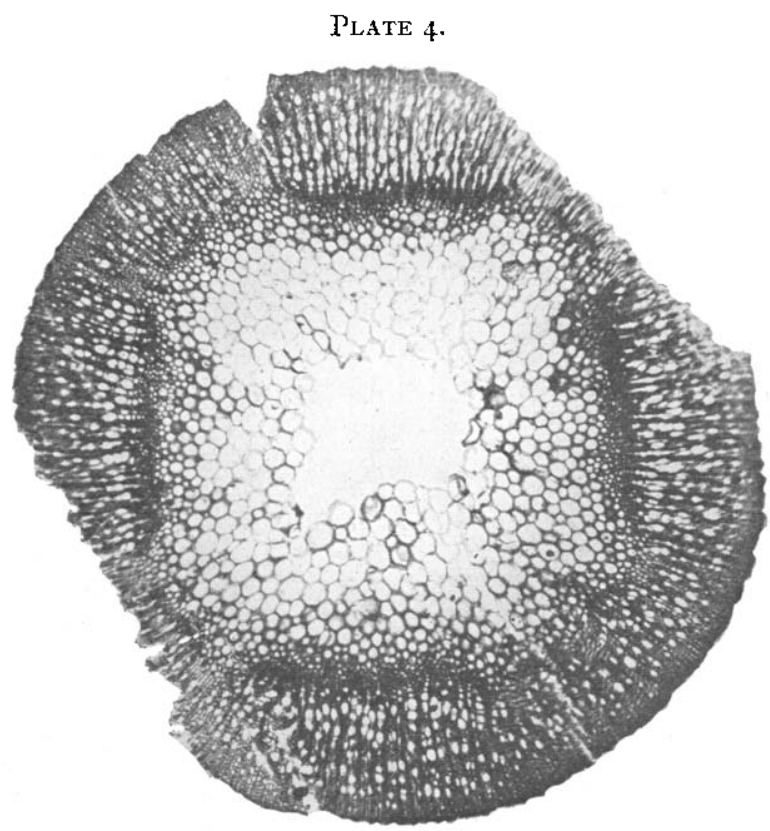

Cunila mariano.

scraped from one side, and the other side shellacked over a length of about $8 \mathrm{~cm}$.; (4) a stem scraped on all sides and one-half of it shellacked; (5) a stem having half its circumference scraped, the other half having the bark intact; and (6) a stalk planted head down. The location proved to be a poor one, the ground not retaining moisture. The place was disturbed, but in spite of this some results were obtained.

Tests No 2 and No. 3 were "planted" on January I I, I9I4, and consisted of about two dozen plant-tops and stems which 
had been broken off by the wind. They were placed on a gravelly bank which was not desiccated by the wind and sun. Some of these stalks were covered with ground up to their branches. In none of the field tests were the tops of the stalks covered to prevent deposition of atmospheric moisture. Test No. 2 contained several stalks of heliotrope (and stems of wild grape vine) which. of course, at this late date were entirely dead. As already mentioned, Herschel found ice fringes on the (green) stumps of

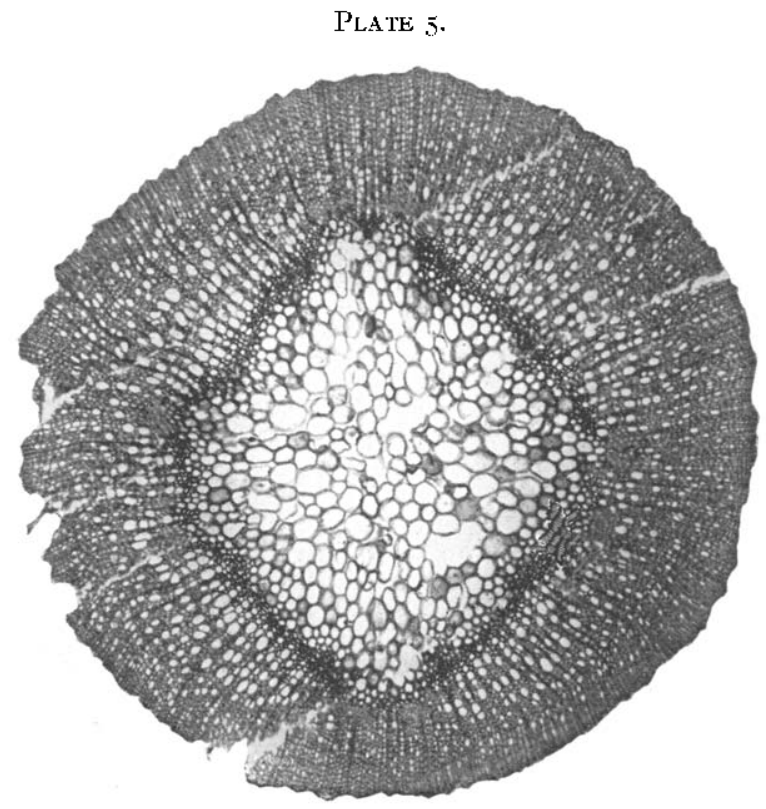

Cunila mariuna.

heliotrope. At no time were there ice fringes formed on the heliotrope (nor on the wild grape stems which were green), especial note of this fact having been made on January 22 and February 2 , I9r4.

The laboratory tests (started on January 3 oth) were made on plant-stems placed in a receptacle containing watcr. In the first and second laboratory tests, "A" and " $B$," the samples were mounted in a small porcelain crucible, as shown in Fig. 2. The plant-stems were fastened into a piece of heavy cardboard by means of Khotinsky cement. The cardhoard was then covered, on 
both sides, with paraffin and sealed (with paraffin) to the top of the crucible. A small pin-hole equalized the air pressure, thus preventing any possible hydrostatic pressure. The protruding stems were covered with a glass beaker, which prevented deposition of moisture from the air.

Two additional laboratory lests were made on plant-stems placed in test " $C$," a test-tube, as shown in the photograph, and "D," a wide-mouthed bottle. In all these laboratory tests the stems were covered to prevent deposition of atmospheric moisture.

Experiments Showing How the Water is Conveyed.-The field observations, "Test No. I," showed that the water is not transferred along the cambium layer or the bark. Ice was formed

Fici. 2.

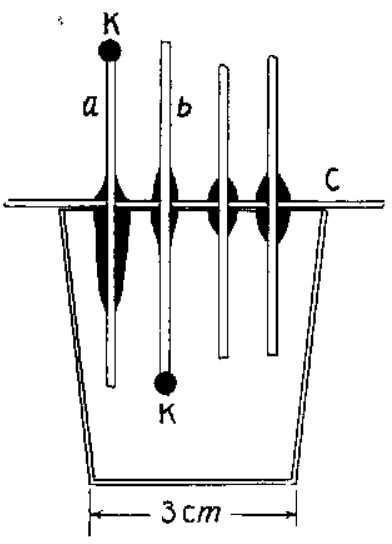

on that half of the stem which was scraped, but none was formed upon the part (whether scraped or unscraped) which was covered with shellac. This observation was confirmed on different occasions, especial note of this fact having been made (Test I, Nos. 3 and 4 ) on January 8th, I2th, and 27 th, and February 2nd and $3 \mathrm{rd}$. In No. 2 of this test the ice forced out the shellac at the juncture of two branches on February 3 rd. On these dates (as well as others which would be too tedious to record in this paper) my notes show that ice fringes, large and small, were formed upon numerous plants contained in the plats described as Tests $\mathrm{I}, 2$, and 3 .

The laboratory tests " $\mathrm{A}$ " and " $\mathrm{B}$ " showed that, starting with stems which had been drying for nine weeks in the labora- 
tory, the moisture is transferred very rapidly after placing the stems in water. In Test "A" (see Fig. 2), fout scraped samples were thoroughly covered with an impervious cement at the point of contact with the cardboard $(C)$. About $2.5 \mathrm{~cm}$. of the stems extended above the support. The next morning (Jantuary zoth) two samples were found thoroughly soaked They were from the upper part of the plant, hence thin-walled and less "woody." The third sample, which was taken from near the root, was inactive. The fourth showed slight moisture at the top, and by night ( 24 hours in all) this sample was thoroughly soaked.

The second laboratory test " $\mathrm{B}$ " consisted of the two most active samples of Test $A$ thoroughly dried and covered with cement $(K)$, as shown in Fig. 2, and placed in water containing a red dye. The sample, $a$, was covered at the top, $K$, so that the water would have to come out at the sides. The sides of the immersed part of this stem were covered with cement, so that the water would have to traverse the sap tubes in order to reach the top. The immersed end of sample $b$ was covered with cement so that the water would have to soak in through the sides in order to traverse the stem.

The next morning, February 3, I9I4, (uncolored) moisture was observed on the sides of $a$, and the top of $b$ showed the red dye. Evidently the water had traversed the stems to a height of about $3 \mathrm{~cm}$. by capillary movement. In the subsequent tests, " $C$ " and "D," the stems were more than $6 \mathrm{~cm}$. in length, and it was found that the water rose to a height of $5 \mathrm{~cm}$. However, when uncovered and exposed to the wind the moisture did not rise higher than $\mathrm{I} \mathrm{cm}$. to $2 \mathrm{~cm}$.

Further Tests Showing That the Water Comes from Within the Stems.-There are several observations which indicate that the water required for the formation of ice fringes comes from within the stem, and that it is not caused by accretion or sublimation, as in hoar-frost. One of the observations applicable to this question was made in connection with the laboratory tests, " $C$ " and " $\mathrm{D}$," discussed elsewhere in this paper. The morning following the formation of the ice fringes on the Cumila stems it was observed that considerable water had disappeared from the glass receptacles. The glass beakers covering the stems were perfectly clear, showing that no water vapor had condensed (and frozen) upon them. Evidently the ice fringes had been 
formed from the water which had disappeared from the glass receptacles.

Another observation (January 6th) was on a plant (in the woods) surrounded with green moss and well covered with leaves of trees. The stem had several large ice fringes which were hidden by leaves. The leaves were covered with hoar-frost.

A very convincing field test was made by painting the stems with asphaltum in turpentine. If the ice formations were the result of condensation of moisture by rapid cooling, then the black paint should have ice formed upon it. In the afternoon of January $3^{\text {th }}$ (the ice fringes having melted as usual) a number of Cumila plants free from bark, situated in various parts of Rock Creck Park, were given a coating of asphaltum paint. "Test No. 2," mentioned elsewhere in this paper, contained several painted stems. As shown in the photographs, the outer edge of the ice fringe is smooth, which could hardly be the case if the formation were similar to that of hoar-frost. On January 27 th it was found that ice fringes on two plants in Test No. 2 had pushed out the asphaltum varnish, which was found adhering to the outer edge of the ice, $\mathrm{I} .5$ to $2 \mathrm{~cm}$. from the stem of the plant.

In Test No. 4 the ice had pushed out the asphaltum and had formed a fringe in the rent in the paint. For some days subsequent to this date there was no freczing weather; but on February 3rd other stalks were found in which the asphaltum varnish was pushed out by, and was situated on the outer edge of, the ice fringe. It may be added that for some days after applying the asphaltum paint the formation of ice fringes seemed to be inhibited.

The field tests ('lest I), described elsewhere in this paper, in which one side of the stem was covered with shellac varnish, showed that the moisture was not conveyed from the ground upward along the outside of the stem.

In view of the fact that the bark is often found pushed out by the ice, these tests with asphaltum seem superfluous; but the persistence with which the hoar-frost theory was presented to account for this ice formation seemed to require a reductio ad absurdum test. The mere fact that hoar-frost is in fine spicules, while these fringes are smooth, should be sufficient evidence to disprove the hoar-frost theory. If sublimation by cooling had been the cause, then the black paint, with its high emissivity

Vol. CLXXVITT, No. Io67-42 
("cooling power"), should have produced a great amount of hoar-frost upon the outside of the paint. The ice fringes were always formed on nights when the temperature was sufficiently low to cause freezing, whether or not there was hoar-frost in the vicinity.

The actual amount of ice formed (see pholographs) is far in excess of what seems possible by the hoar-frost theory. On Jantuary 7 th the ice fringes formed on a single plant were collected and weighed. The ice formation on this plant, on this date, weighed over 5 grammes. The weight of the ice on the latge sample shown in the photograph (Plates 8 to II) is probably between 4 and 5 grammes.

Fig. 3 .
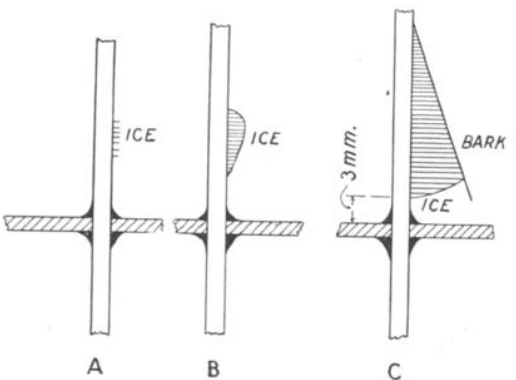

In view of the fact that the stems are dry it is, of course, superfluous to consider the ice fringes to be composed of the "plant juices." The ice is tasteless, in spite of the fact that the plant has a strong fragrance of thymol.

Observations Showing How the Ice Fringe Grows.-One of the most interesting observations was the formation of the ice fringe from its very beginning. This was witnessed by several of my colleagues, who were called in to verify the observations. On a cold morning, February 16 th, the samples in Test "B" were placed outside the laboratory window, and in about 20 minutes the ice fringe was observed to be forming. It consisted of a row of fine hairs extending up and down a length of about $4 \mathrm{~mm}$. of the stem, and projecting out horizontally 0.2 to $0.3 \mathrm{~mm}$. (see Fig. 3, $A$ ) These filaments were visible only when viewed against sky light, and they melted immediately on lifting the glass cover. The fringe did not appear to form at the line, Fig. I, 
where the pith is closest to the surface of the stem. This experiment was repeated again during the evening. Within half an hour after placing the samples (Test " $B$ " with additional samples) in the cold air one stem showed several fringes in the form of thin, transparent " teeth," each one being about $\mathrm{r} 2 \mathrm{~mm}$. in length and about $\mathrm{I} \mathrm{mm}$. in height. Another stem showed a fine hairy fringe which was visible when viewed against a gas light. Within half an hour this hairy fringe appeared to be solid, with some of the fine hairs extending horizontally ontward through the solid "tooth" of ice, as shown in Fig. 3, B. This, of course, is the general structure of the fringes. By the next morning numerous wide fringes had formed on these stems. Tn another sample the tooth of ice pushed out a narrow strip of bark similar to the illustration given in Fig. $3, B$. In these test the receptacle containing the water was small, and hence the whole cooled very rapidly and the water froze, which prevented the growth of the ice fringes. It is to be noticed that the ice fringe forms some distance up the stem, at a point where it cools the quickest and where the moisture has risen to about its maximum height.

Test "C," started February $17^{\text {th }}$, contained half a dozen samples of Cunila and a stem of an "aster" in a large test-tube. The test-tube was imbedded in wool to retard cooling and freezing. Within I 5 minutes after placing this test outside of the laboratory window two small fringes, $1.5 \mathrm{~mm}$. long and about $0.3 \mathrm{~mm}$. high, were noticed when viewed against the sky light. 'This test was prolonged for some days and nights, and a photograph was taken (February I8th, Plate I2), showing that the stems, in water, form ice just as they do when attached to the roots In this photograph, which is magnified slightly (I.2), about one-third of the upper part of the largest fringe is broken off. These fringes appear a little more transparent than usual, owing to melting while taking the photograph.

No ice or moisture was formed on the aster stem, which is in agreement with the field observations, where in only one instance was there an ice fringe found upon an aster stem. In this field sample of aster there was but little ice, which was very close to the ground. In Test "C" all the Cunila stems showed moisture, and ice was formed on nearly all of them. The thinnest stems formed the most ice.

Test " D," started February I7th, consisted of an assortment 
of Cunila stems, ten in number, mounted in a large, wide-mouthed bottle, having a capacity of about I litre. This bottle was wrapped in hair felt, in a box, which was kept outside the laboratory window. The stems were supported as usual by the cardboard lid, which was thoroughly covered with paraflin. The protruding stems were covered as usual with a large glass beaker, which rested closely upon the felt.

As may be seen from Fig. I and Plates 4 and 5, the Cumila stem, on drying (shrinking), splits easily into four parts, owing to the small amount of wood fibre at the four sides of the stem. One of the samples used in Test " $D$ " was a splinter, consisting of one-quarter of the stem, about $6 \mathrm{~cm}$. in length, with a line of pith adhering to the inner side. On the following morning, and on sulbsequent days, this splinter showed a Iringe of ice on the

FIG. 4 .
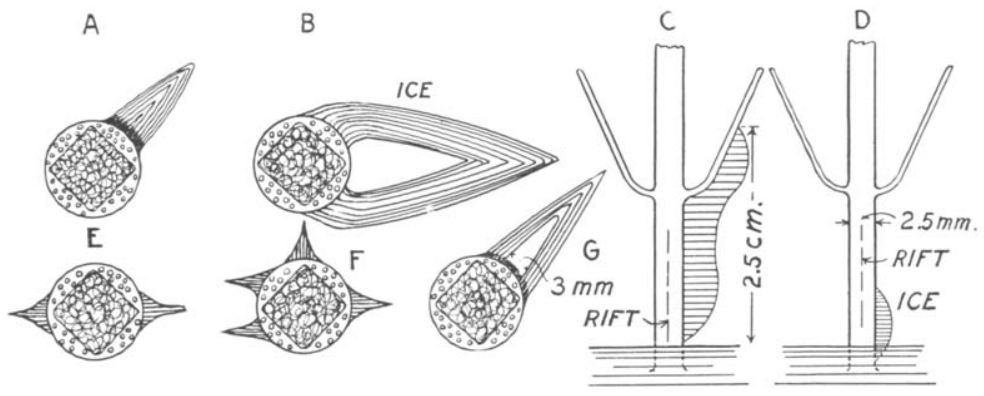

wooly surface, but at no time was there ice formed on the pith. One sample consisted of one-half of the stem, as shown in lig. 4 , $A$, and on February 20 th a solid fringe or "tooth " of ice was found projecting out to a height of $31 / 2 \mathrm{~mm}$. It was about $2 \mathrm{mnnl}$. wide at the base and extended perhaps I $\mathrm{cm}$. up and down the stem. An interesting feature (which to the writer became a common observation) was that the ice fringe did not always start at the "corner" of the stem where the wood is the thickest; neither did it start at that part of the stem where the wood is thinnest, but at a mid point, as shown in Fig. 4, $A$. From the microphotograph of a thin section of the stem it appears that the largest part of the ice fringe may form at the point where the sap tubes lie nearest the surface, hence where the moisture can be supplied the most easily. 
Another sample in Test "I)" consisted of a thin stem ( .5 mm. cross-section) which was split into four segments for a length of about $2 \mathrm{~cm}$. The ends of the stem were intact. My notes, recorded on the morning of February 2oth, state that "one can see through the cracks in the stem. Two ice fringes are formed, extending outward to a height of $7 \mathrm{~mm}$., and extending $\mathrm{I} 2 \mathrm{~mm}$, vertically along the axis of the stem; lut they are not formed in the cracks." In fact, the point of attachment of the fringe to the stem, as examined under a reading glass, did not even extend close to the cracks.

In some of the samples in Test "D" the stems were entircly free from bark (see the photographs of Test "C"), while some were covered with bark. In the latter samples the ice pushed out a narrow strip ( $1 \mathrm{~mm}$. wide) of bark, as shown in Fig. 3. $C$. This seems to be the usual manner in which the stems are stripped of bark. The bareness of the stem, however, does not seriously affect the ice formation, as may be noticed in the accompanying photographs. One sample had a fringe $3.5 \mathrm{~cm}$. in length and 2 to $3 \mathrm{~mm}$. thick at the base. When the bark is still intact, the icc formation appears to occur most frequently at the "corners" of the stem (see Fig I). In the bare stems the ice was sometimes found ('lest "D," February $I 7$ th) to be formed well around the stem, as shown in Fig. $4, B$; and numerous field observations showed that this is the result of the fusion of two fringes, leaving a wedge-shaped frec space between them. The commonest form, however, is shown in Fig. $4, G$ (field observations of January 6 th and 8 th), in which the ice ribbons were described as a composite of thin sheets which were estimated to be $0.3 \mathrm{~mm}$. in thickness. The open space was perhaps $3 \mathrm{~mm}$. wide at the base. The base appeared to be a solid shell $0.5 \mathrm{mmm}$ in thickness. One could easily look through this wedge-shaped opening. Sometimes these fringes adhere well to the stem, so that the ribbon breaks across the open space. After sunrise the stem warms rapidly, which no doubt explains the ease with which the ice ribbon is usually separated from the stem.

The bare stems used in this test were old stalks from which the bark had been separated by previous ice formations in the woods. Evidently the laboratory test did not interfere with the ice formation. The roots are not nccessary for the production of the ice fringes. As a matter of fact, the stalk and the nearby 
roots are dead, although the rest of the plant (new growth) is perennial.

The ice usually formed on the flat side of the stem, but, as already mentioned, it often was found to cover the whole side, as shown in Fig. 4, B. In some stalks the ice "tooth" was found (note of February 17th) to have formed near the "corner" of the stem, as shown in Fig. 4, $A$. Other icc teeth were observed in the process of formation, as shown in Fig. $4, E$ and $F$, the ice being solid, about $3 \mathrm{~mm}$. in length and half a millimetre in height. Fig. 4, E, was observed on Test " B," February I 3 th; and Fig. $4, F$, was found in the field on January I I, I914. In view of the fact that the general notion is that the stems are split by the frost, it is important to notice that in these laboratory tests none of the stems were rifted by the icc formation. The rifted stems used in these tests were samples which had cracked on drying and shrinking, after having been in the laboratory.

The ease with which these stems became saturated with water after having been drying for weeks is another item worth noticing. All the stems used in Tests " $C$ " and " $D$ " had been in the laboratory for some time. Some of them had been gathered in November, I9I3, and had been freed of bark by previous ice formations.

It is generally supposed that the ice is formed more easily in the fall (when the plants are fresh). than in the late winter. This seems to be true, to some extent, according to my field observations and to my laboratory tests. In the latter, Tests "A " and "B," the ice did not seem to form so abundantly after the stems had soaked for some weeks. It seemed as though the sap tubes became clogged, or the plant had begun to decay.

Although the laboratory tests were continued after February 2 ist, no records were kept, and at the risk of being prolix the notes of the last two mornings are given herewith.

On February zoth (warm and rainy the first part of the night, cold and freezing in the morning) moisture and ice fringes werc found extending 2.5 to $3 \mathrm{~cm}$. up the stems. Test " $\mathrm{C}$ " contained 5 Cunila stems and one "aster" stem. Ice fringes were found on four of the five Cunila stems, but no ice or moisture was found on the aster stem. There were two to four fringes on each stem, some of the fringes being $1 \mathrm{~cm}$. wide,-i.e., extending outward horizontally I cm. from the stem. The last laboratory observations were made on the morning of February 2 I, I9I4. Tests 
" B," "C," and "D " were under observation, having, of course, been started the previous evening. "lest " $D$ " had ice fringes on seven of the nine stems of Cunila. The thick Cunila stumps did not seem to be able to form ice, and there was no moisture on them. Test " $\mathrm{C}$ " had ice fringes on all the Cunila stems (there were four stems), but no ice or moisture was on the aster stem. The aster is one of the common plants found growing near some Cunila stalks, but was so badly broken that it was not identifiable with any of the numerous asters which abound in the locality. Some stems had four fringes, but no ice was observed in the cracks which were in one of the stems. Some of the fringes were curled back against the stem.

Test " B" showed ice fringes on two of the three stems under observation. The third stem was a very thick one, which showed a fine line of ice just starting. The fringes were small, being only about $3 \mathrm{~mm}$. long and 2 to $3 \mathrm{~mm}$, high.

The peculiarity of the fringes, on February $2 I$ st, was that in all three tests (" $B$," "C," and " $D$ ") the fringes were small, and the outer edges were curved back against the stem, as shown in Fig. 5. A. This seems an interesting observation, for it serves to explain the peculiar ice loops one so frequently observes in the field. They no doubt start as a thin fringe (as in the laboratory test of February $2 \mathrm{Ist}$ ), one side of which grows faster than the other, thus forming a curved fringe, as shown in Fig. 5, $A$, which in some cases seems to frecze against the stem. As more ice is formed the loop is merely enlarged, as shown in Fig. 5, $B$, which is a field observation (January 18,1914 ) on a rifted stem where no ice was formed in the rifts. This loop was jointed at the ends. A still more remarkable formation (observed January I8, igi 4 ) is shown in Fig. 5, C, which also showed no ice formed in the rift. In this sample it was especially noted that the loop was not jointed. $\Lambda$ further illustration of the composite character of the fringe is shown in Fig. $5, D$ (field olsservation January i8th), in which one side of the fringe has intermittently grown faster than the other side, thus forming a wavy, fluted surface, while the other side is smooth. My notes of Jantuary I8th state that the loop is usually jointed at the outer edge (Fig. $5, B$ ), the fringe usually starting near the rift.

These illustrations seem to indicate that the ice fringe has its beginning in a row or several rows of fine, hair-like filaments of 
ice, as shown in Fig. 3, A. These filaments of ice, which remind one of the finest filaments of mold, increase in number, thus filling in the gaps, and form a contintous film of ice. They extend upward and downward along the axis of the stem; and they widen out, thus producing the sharp, wedge-shaped formation of ice which one finds in the early stages of growth of ice fringes. It is possible that when the plant is exposed in the open fields the fine, hair-like filaments of ice, which constitute the first stage of the fringe, are not formed, and that the thin, solid, tooth-like formation constitutes the beginning of the ice fringe. As shown by the laboratory test, however (Test " B " mentioned on a previous page), the ice iringe passed through both stages of growth. At

Fig. 5 .

A

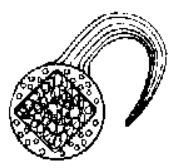

C

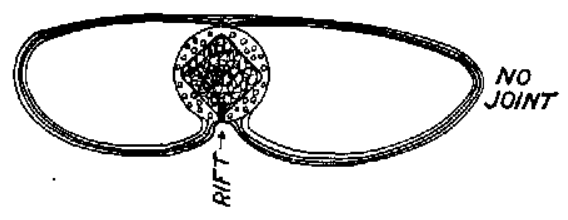

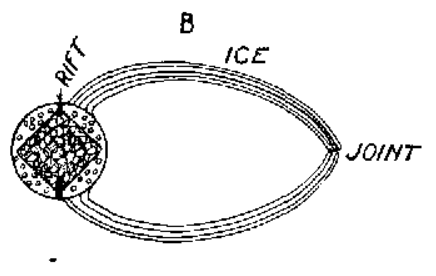

D

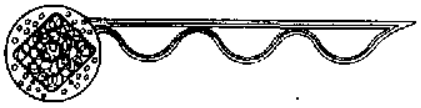

7 r.M., February i6th, the fine, hair-like filaments were visible. At 7.30 P.M. these filaments had multiplied and coalesced into a solid film, with hairy streaks in it, as illustrated in Fig. 3, B. The following morning the fringe had grown larger than the sample shown in the photograph (Plate I2) of Test "C."

These laboratory tests serve to explain the filamentous structure of the mature ice fringes, which are always found to be fibrous, the ice ribbon often breaking into several ribbons. This is well illustrated in the large ice fringe shown in the photograph (Plate 7) of Test "C." The light, horizontal lines show the edges of the individual fringes. In fact, this particular sample contained large, open spaces, in spite of the fact that it was not more than $2 \mathrm{~mm}$. in thickness,--i.e., the thickness of the sten. 
The formation of the ice filaments (Fig. 3,A) might be used as evidence in supporting Le Conte's theory of a "projectile force" which produces the fringe. The difficulty then arises in attempting to find the cause of the projectile force. The physical forces now familiar to us secm sullicient to account for the phenomenon, without invoking unknown forces. These known physical activitics are: ( 1 ) cooling of radiation, (2) a rapid capillary movement of water through the interior of the plant, and (3) sufficient moisture in the soil so that the capillary forces can bring moisture to the surface at a greater rate than that at which moisture passes into the air by convection and by evaporation. The capillary movement of water may possibly be accelerated by the temperature gradient in the stem, which is cooler on the outside.

The main difficulty in this explanation of the cause of ice fringes lies in the fact that the second stage in their formation is an apparently solid wedge of ice (see, however, Fig. $3, B$ ), whereas the mature fringe is fibrous in structure, is very friable, and often separates into a serics of thin, wide ribbons, as thin as tissuc paper. This fibrous structure, however, may be the result of re-formation by variations in air temperature, by evaporation, etc., which produces the white fringe shown in the photographs. The laboratory formations never appeared quite so white. The great transparency of the sample, Test "C," shown in the photograph, Plate 12, is owing to melting while taking the photograph. The field specimens differ greatly in translucency. On a cold, frosty, cloudy morning (January I 8 th?), the atmosphere having a "damp" feeling, the numerous ice riblons, 2 to $3 \mathrm{~cm}$. in length, were conspicuous for their great transparency.

What Determines the Location of the Jce Fringe upon the Stcm?-The ice fringe is ustually found to adhere looscly to the stem. It seemed to continue to increase in size even when the ground surrounding the plant was frozen to a depth of $\mathrm{t}$ to $2 \mathrm{~cm}$. As was found by Le Conte, the ice formation ceases its growth after the ground has become frozen to a considerable depth. The moisture in the stem is then found to be frozen, and ice is found in the (rifted) stems. On very cold mornings the ice fringe extended down to the ground (observation of January i Ith). The closeness with which the fringe approaches the base of the stem depends, of course, upon the temperature of the ground. 
The height to which the fringe can form seems to be governed by the rate of capillary movement of the water, and the rate of evaporation (and convection) from the surface. In the laboratory tests where the plants were covered and protected from the wind the moisture rose 5 to $6 \mathrm{~cm}$. in the stem; but on removing the cover evaporation reduced this height to $\mathrm{I}$ to $2 \mathrm{~cm}$. When the soil was wet the ice ribbons were the widest. For example, on January 7 th a width of about $4 \mathrm{~cm}$. (I $\mathrm{I} / 2$ inches) was recorded. After several days of cold and freezing, the ground having become quite dry, the ice fringe was short and did not rise more than I. $5 \mathrm{~cm}$. above the ground. There is evidence that the ice fringe may form on a definite position of the stem. For example, one stem which on February $I 7$ th formed a large fringe on the "outside" (see photograph Test "C" ), i.e, near to the glass cover, was rotated 180 degrees. The next morning the ice fringe was found to have formed on the "inside," i.e., on the same side of the stem, showing that proximity to the glass cover did not change the location of the fringe upon the stem.

The location and the amount of the ice formation are evidently determined by the ease with which the moisture can be supplied from within the plant. $\Lambda \mathrm{n}$ examination of the cross-sections of plant stems showed that sap-tubes may be located very close to the outer wall of the stem. One would expect this to be the starting point and the most prolific source of production of the largest fringes. In the laboratory test-sample, the stem showing this property was one from which the bark had been scraped, and the abrasion may have leen deeper on the side which produced the most ice.

In the field one strong, weather-beaten plant (stem without bark, $2.5 \mathrm{~mm}$. in diameter), situated on a steep bank, was observed, all winter long, to form the ice fringe on one side. It was split as shown by the dotted lines in Fig. 4, C, but no ice was observed in the rift. Sometimes the base of the ice tooth was almost solid and embraced half of the stem, as shown in Fig. 4, B. After a rain, when the ground was quite wet, the ice fringe extended 2 to $2.5 \mathrm{~cm}$. up the stem and out along a branch (observation of January I Ith), as shown in Fig. 4, $C$. On other mornings when the ground was dry and powdery there was but little ice formed above the loose earth, which continued sliding down the steep, bare hillside. The ice fringe, however, whether a wide 
ribbon or a short, wedge-shaped tooth, Fig. $4, D$, half buried in the shifting dry ground, was always formed on the same side of the stem. The clump of (three or four) plants of which this was one stem never formed such long ribbons as was to be olsserved on other stems which were situated on a lower level on this same bank, where the ground was always moist. The plants of Test 2, described elsewhere, were located on the lower level of this steep hill, also stumps of Cunila from which the tops had been cut. No ice was olserved to form on the cross-section of the stump; but long, curled ribions of ice continued to form along the side of the stem which was on a level with the ground. The soil itself

PlAT: 6.

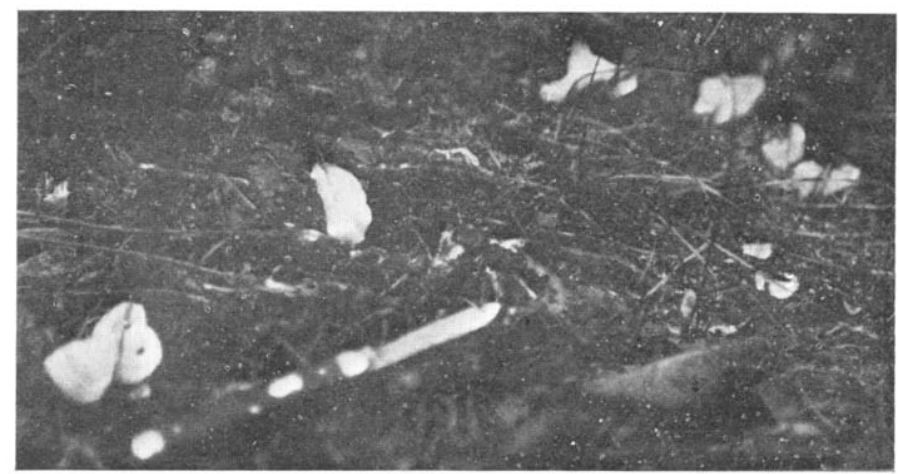

formed excellent samples of "ground ice." It was, therefore, an interesting sight to sometimes observe the ice fringes from the stumps of Cunila protruding out over the ground ice. The ground ice formed only after rain when the ground was wet, i.e., contained a certain amount of moisture.

Description of Photographs of Ice Fringes. - The attempts at photographing the ice fringes as they occurred in the woods were far from satisfactory. This was owing to the fact that at $8 \mathrm{~A} . \mathrm{M}$. the illumination was low. A wide stop was used in the camera, and consequently the objects are in focus only in the centre of the photograph. They serve the purpose, however, to illustrate their general appearance as found in the woods. The ice fringes are viewed at an angle of almost 45 degrees. However, a general idea of the size of the fringes nay be obtained 
by comparing them with the accompanying pocket-knife, which is about I $4 \mathrm{~cm}$. in length.

The photograph, I'late 6, was obtained on Jantary 7 , r9I4. It is typical of what one finds as regards sizc and general appearance of the ice fringes. The fringe in the lower left-hand corner

PLATE 7.

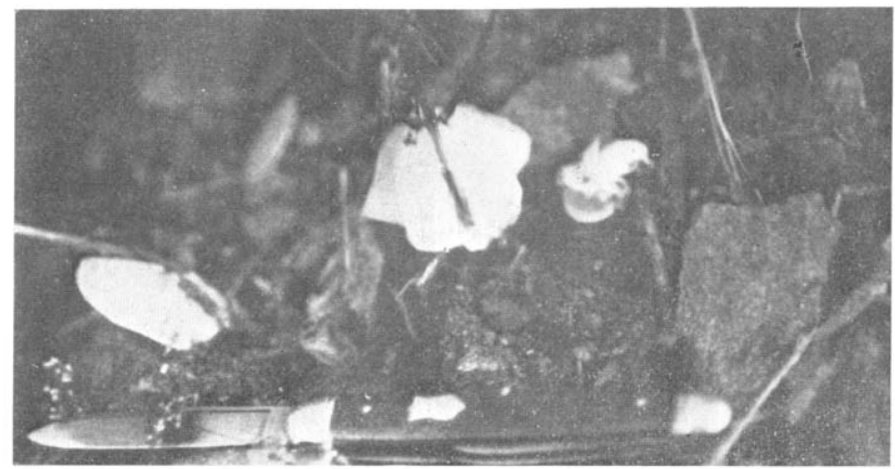

is composed of three whorls; the open space in the fringe nearest the knife is shown by the round dark spot in the centre. The brightest ice fringe in the stalk in the centre of the picture is not unlike the large sample shown in l'latcs 8 and 9 . This photograph

\section{PLATE 8.}

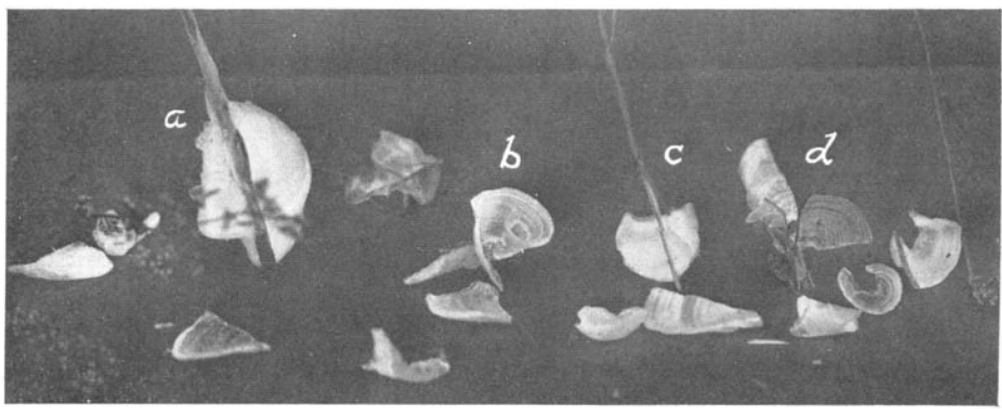

shows seven stalks with ice fringes. One formation in the lower right-hand corner of the photograph is broken. The Cunila stalk upon which this fringe was formed (the stalk with the three branches) shows the bark pushed out at the base of the stem, with some ice still adhering to it. 
I'late 7 was obtained in the middle of January. The ice formation in the centre of the photograph contains four beatufully folded fringes, the markings of which are, unfortunately, lost in the print.

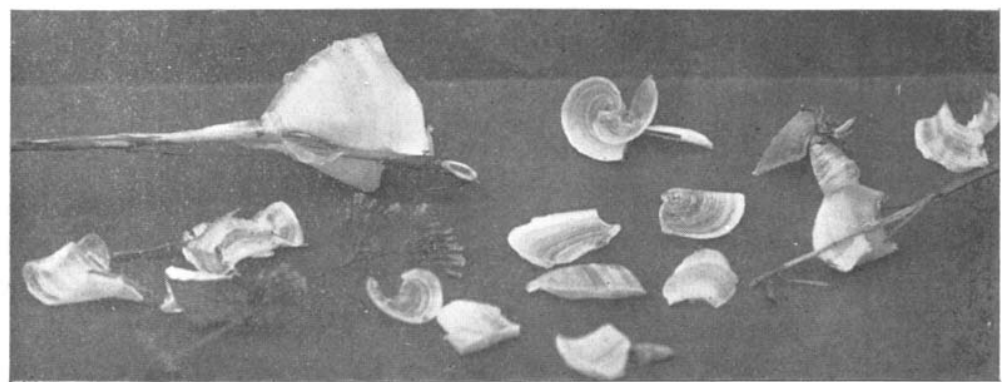

The finest photographs (Plates 8, 9, 10, and I I ) werc obtained by collecting a number of ice fringes one cold, frosty morning (Jantuary 6, I9I4) and having them photographed at the Bureau of Stanclards. Grateful acknowledgment is due Mr. E. D. Tillyer

Plate 10.

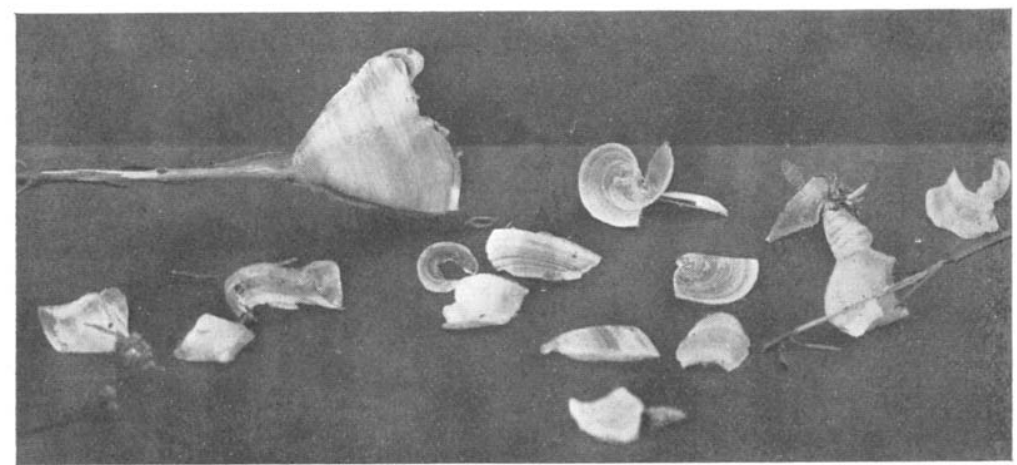

for his painstaking care in making these photographs. which no doubt are the finest records yet obtained of these beautiful ice formations.

In Plate 8 the four most conspictous ice fringes are lettered $a, b, c, d$, which makes identification easy in Plates 9 , Io, and I 1 . 
In these plates the ice fringes were photographed from different sides. In Plate 8 , a, it may be noticed that the stem is free from bark.

In Plate $9, a$, an extremely thin, delicate fringe may be noticed protruding from what appears to be a rift in the stem, but what in reality is a piece of bark. It is an excellent illustration of the second stage in the formation of the ice fringe as described on a preceding page and illustrated in Fig. $3, B$. Plates Io, $a$, and $\mathrm{I} \mathrm{I}, a$, give further views of this ice formation, which consists

\section{Plate i .}

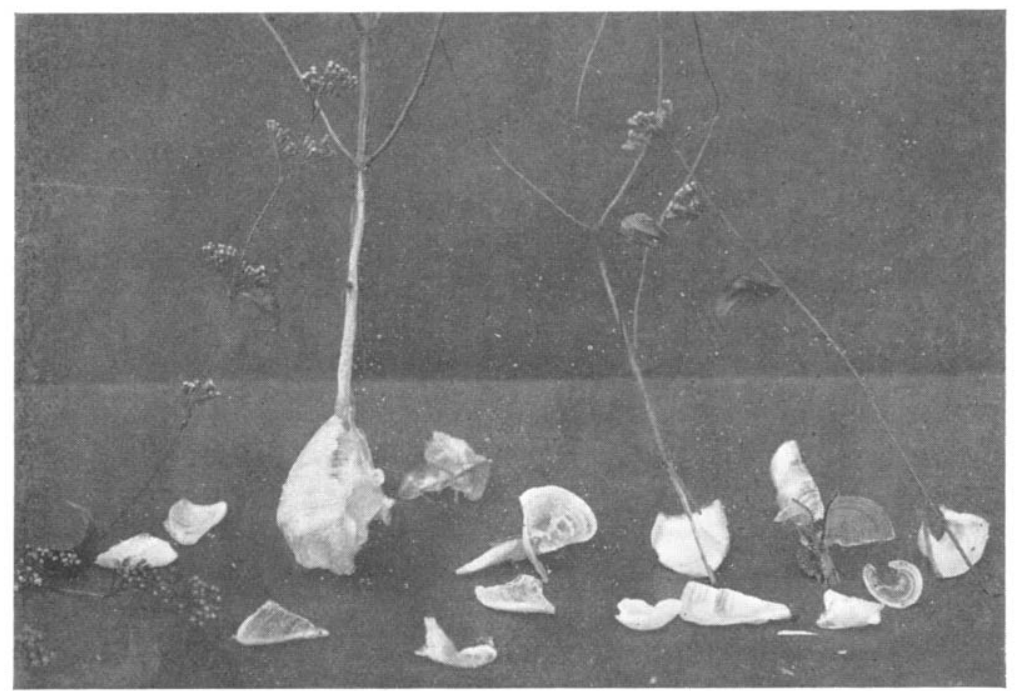

of two large fringes, twisted and whorled. In Plate Io, $a$, the oft-mentioned thin, wedge-shaped fringe (see Fig. 4, $E$ and $F$ ) is shown to advantage, protruding (upwards in the photograph) from above the large fringes. The Cunila stalk $a$, shown in these plates, is typical of what one finds after several ice formations, when the stem is well stripped of bark. The stem is 2.2 mm. in diameter and it is not rifted. $\Delta s$ shown in Plate Io, $a$, the "width" of the fringe adhering to the stem is $3 \mathrm{~cm}$. It extends out horizontally $3 \mathrm{~cm}$. from the stem. The distance from the stem to the extreme distal end of the loop is $4 \mathrm{~cm}$.

Plate $8, b$, consists of three splinters, united at the base of the 
stem. 'They are, of course, the remnants of the stalk, which had long since disappeared. The dark line in the wood is the pith, which is shown to better advantage in Plate I,$b$, and Fig. 6 . Plates 9 and ro show the pith side of another splinter. We thus have a photographic record of the ice formation, not only upon the unrifted stalk, but also of the formation of the rifted stalk (Plates 8, 9, IO, and $\mathrm{I}, \mathrm{c}$ ) and of the formation upon the bare splinters, This is an tnusually interesting ice formation. The peculiar whorl in the centre (Plates 9 and IO, $b$, are top views) is the meeting-point of two fringes (see Fig. 6), both of which began curving clockwise. The extreme thinness and the great transparency are to be noticed (see also Plate $3 . d$ ) by the light. and the dark streaks throngh the fringes.

FIr. 6.

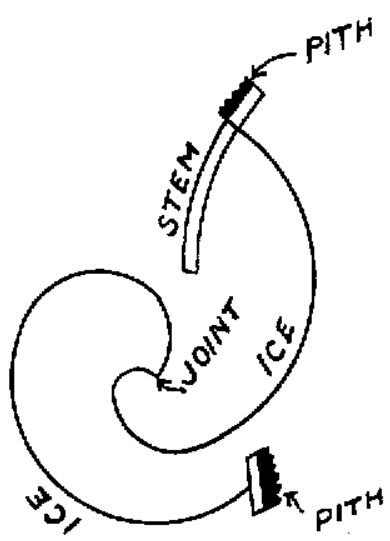

The small ice fringes on the stalk shown in Plates 8,9 , I0, and $I I, c$, are of interest because they occur upon a thin stem which is split into two parts, the rift being easily distinguished in the photographs. In fact, most of the rift is above the ice fringes. This ice formation is also conspicuous in having pushed out some of the bark, as illustrated in Fig. 8, c. This is an excellent photographic record showing that the ice is not formed upon the pith (Fig. 8, b) or in the rift of the Cunila stem.

Plates 8, 9, Io, and I $1, d$, give a further illustration of the formation of ice fringes upon fragnents of stems of the Cunila. The sample is a very small one. The stump of the stalk had to be 
cut out of the ground in order to obtain the fringes. Some of the ground is still adhering to the stem. One of the fringes is broken off. The extremely thin, translucent fringe (it appears to be dark, owing to the dark background) on the right-hand side of Plates 8 and $\mathrm{I} I, d$, is an excellent photographic record of the manner of growth of the ice fringe, as rescribed on a previous

Plate 12.

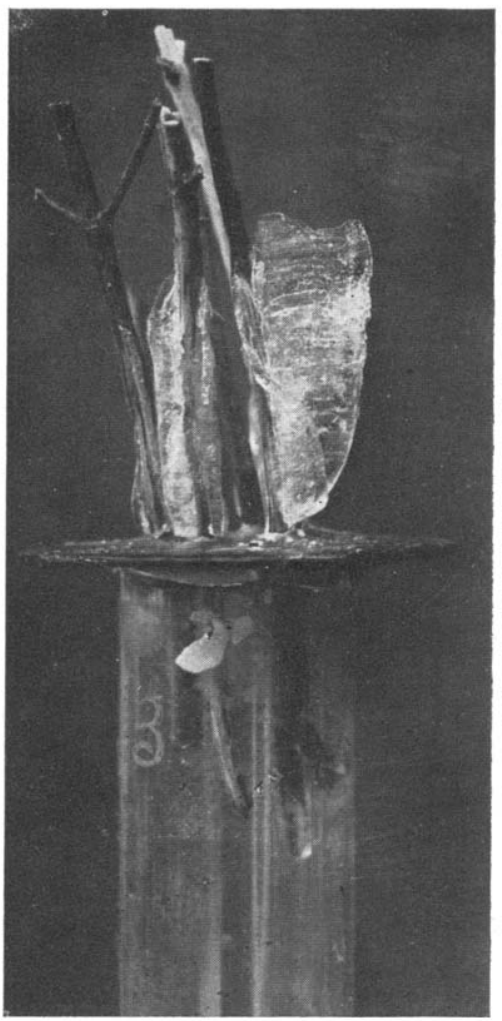

page. The growth of the fringe is along a straight edge, which appears almost horizontal in the photograph. This, however, is partly owing to the peculiar curvature of the fringe. The distal edge is straight and smooth, just as it started when near the stem. The photographic record is, therefore, an excellent contradiction of the hoar-frast theory of accumulation. In the tests with the asphaltum already described the ice fringe had a similarly 
formed straight edge. The dark streak along the fragment of stem is pith. The ice fringe is upon the woody side of the stem.

Plate I I shows the upper parts of the stem, a few leaves and the showy seed capsules. All the plates show fragments of ice fringes, the bright and dark streaks of which are owing to the difference in thickness and hence in transparency of the ice.

Plate $\mathrm{I} 2$ is a photographic record of the laboratory Test "C." It was taken by the writer February 18 , I9I4. The test-tube was about $20 \mathrm{~mm}$. in diameter, which gives one some idea of the dimensions. The test is described on a preceding page. This

Fig. 7.

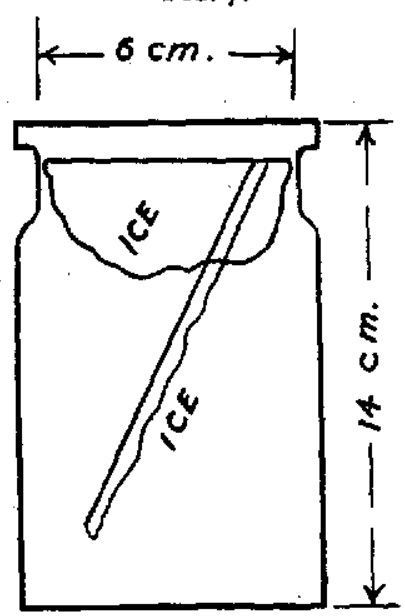

record is of interest mainly in showing that the Cunila stems, after having been in the laboratory for some months, form ice fringes, just as they do when attached to the roots.

Ice Formation in a Large Body of Water.--In view of the possibility that the ice formed at the bottom of a river (the Anchor ice mentioned at the beginning of this paper) may be owing, in part, to some other cause in addition to the high emissivity of the river bottom, it is desirable to call attention to a peculiar formation of ice as the result of cooling and refrigeration in a body of still water.

In Test " $D$," already described, the receptacle containing the water was a wide-mouthed bottle, $6 \mathrm{~cm}$. in diameter at the top and about $14 \mathrm{~cm}$. in height. The bottle was wrapped in hair felt and Vor. CLXXVIII, No. 1067-43 
tightly packed in a box. Cooling was therefore mainly by conduction and radiation from the top. On one occasion it was observed that instead of the ice freezing solid across the top, there were several extremely thin "curtains" of ice suspended in the water, as shown in Fig. 7. They were visible only in intense sunlight. Several thin, narrow, saw-toothed blades extended far down inside the bottle. They seemed to take the line along which refrigeration occurred, as a result of cooling, principally by conduction and radiation at the top of the vessel. It would be desirable to determine whether the density of these fine ice spicules is the same as that of a large mass of ice.

\section{SUMMARY.}

This paper deals with the formation of ice fringes upon the Dittany (Cunila mariana). The data presented are based upon experiments and observations in the field and in the laboratory.

It was observed that the ice fringes are formed when the temperature falls to freezing point $\left(0^{\circ} \mathrm{C}, 3^{\circ} \mathrm{F}\right.$.) ; but they are not a function of the hoar-frost which may be present upon the ground.

The ice fringes do not form upon the side of a splinter which contains the pith or upon the line of fracture, but upon the outer woody surface. The formation of the ice fringe, however, is not a function of the surface condition of the stem. The stem is frequently found to be cracked, but usually no ice protrudes from the rifts.

The growth of the ice fringe ceases when the ground is frozen to a depth of 2 to $3 \mathrm{~cm}$., and when the moisture in the stem is frozen.

The size of the ice fringes and the height to which they extend above the ground depend upon the rate of evaporation from the stem and upon the amount of moisture in the ground. Over 5 grammes of ice may be formed upon a single plant during a single night.

Photographs are given of ice fringes formed upon stems which had been kept in the laboratory several months. They show that the ice may be formed upon stems without the roots. Hence the ice is not formed as a result of hydrostatic pressure exerted by the roots, which are perennial. 
All the observations are in agreement in showing that the moisture arises in the stem as the result of capillary attraction. The height ( $\mathrm{I}$ to $5 \mathrm{~cm}$.) to which the moisture can rise within the stem is governed partly by the rate of evaporation from the surface.

Microphotographs of thin sections of plants are given, which show the structure of stems of plants which do not form ice fringes; also microphotographs of sections of stems of plants which form ice fringes. It is shown that those plants which form ice fringes the most readily and in the greatest abundance have the most sap-tubes.

The ice fringe is a composite of a number of very thin ribbons. In the laboratory the formation of the ice fringe was observed from its very beginning. The first stage in the production of the ice fringe consists of a single row of fine, hair-like filaments of ice. This row of ice filaments lengthens, up and down the stem. The filaments increase in number, thus forming a solid wedge-shaped tooth of ice, which constitutes the second stage of development. In the third stage of development the wedgeshaped tooth of ice widens and increases in length, as the result of freezing of the water which continues to soak out of the stem.

There appears to be no difference between the formation of these ice fringes and the "ground ice" formed on wet soils, other than that in the latter a particle of gravel usually forms the nucletus to start the congelation. In both cases the moisture is brought to the surface by capillary action. When the rate of supply to the surface is more rapid than the loss by evaporation, and the air is at a sufficiently low temperature, ice is formed.

Washington, D. C., June 25, I9I4.

Phase Compensation. G. H. EARdLeY-Wilmot. (Electrician, lxxiii, 5I.) - The different kinds of plant available for phase compensation are considered, such plant being classed as (I) that which may improve the power factor of the system as a whole, and (2) that which is applied to individual motors. The overexcited synchronous motor is first considered, the effects being illustrated graphically and by specific instance. Reference is then made to condensers, and, lastly, a case is taken where a rotary phase advancer is used. It is pointed out that the type of plant to be adopted must depend on the circumstances of each case, as it is impossible to lay down any general rule. 